\title{
Association between NMD3 and symptoms of Parkinson's disease in Chinese patients
}

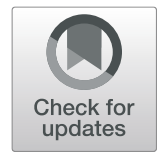

\author{
Hui Wu, Hui Li, Zhiqiang Shi, Jiajia Tang, Shuya Mei, Tianyi Ai and Zhenzhou He* D
}

\begin{abstract}
Background: Parkinson's disease (PD) is a progressive neurodegenerative movement disorder that is characterized by motor symptoms such as tremor, rigidity, slowness of movement and problems with gait. Large-scale metaanalyses of genome-wide association studies (GWAS) have identified few susceptibility loci in patients with sporadic PD. The aim of this study was to investigate the association between NMD3 single nucleotide polymorphism (SNP) and symptoms in PD patients in South China.

Methods: A total of 217 PD patients were recruited in this study and genotyped by using the SNaPshot technique and the polymerase chain reaction. All subjects were evaluated by the Mini-Mental State Examination (MMSE), Beijing version Montreal Cognitive Assessment (MoCA), Sniffin' Sticks 16 (SS-16), Hamilton Anxiety Rating Scale, Hamilton Depression Rating Scale, 39-item Parkinson's Disease Questionnaire (PDQ-39) and MDS Unified PD Rating Scale (MDS-UPDRS).
\end{abstract}

Results: NMD3 rs34016896 (C > T) carriers have worse cognitive function than wild types (MMSE: $p=0.042$, NMD3 wild type: $27.44 \pm 2.89$, NMD3 carriers: $26.31 \pm 3.79$; MoCA: $p=0.005$, NMD3 wild type: $23.15 \pm 4.20$, NMD3 carriers: 20.75 \pm 6.68$)$.

Conclusions: The recessive and overdominant model of NMD3 rs34016896 was associated with cognitive impairment in PD patients.

Keywords: Parkinson's disease, NMD3, Single nucleotide polymorphism, Cognitive impairment

\section{Background}

Parkinson's disease (PD) is one of the most common neurodegenerative diseases, affecting approximately $1.7 \%$ of people over the age of 65 , and the annual incidence ranges from 1.5 to $8.7 / 100,000$ in the People's Republic of China [1]. The pathological features of $\mathrm{PD}$ are the abnormal aggregation of $\alpha$-synuclein and the loss of dopaminergic neurons in the substantia nigra [2]. Both acquired and inherited risk factors have been implicated in the death of dopaminergic neurons [3]. Genetic factors play a crucial role in the pathogenesis of sporadic PD. Genome-wide association studies (GWAS) have identified several susceptibility loci for PD [4-6]. Genes such as $L R R K 2$, SNC A, etc. have been associated with the pathogenesis of PD $[7,8]$. Marie Y. Davis reported that GBA variants predicted a more rapid progression of cognitive dysfunction and motor symptoms in patients with PD [9].

\footnotetext{
*Correspondence: sandyhezz@126.com

Department of Anesthesiology, South Campus, Ren Ji Hospital, School of

Medicine, Shanghai Jiaotong University, 2000 Jiangyue Road, Shanghai
} 201112, China
Recently, variants at NMD3 were found to be related to substantia nigra neuronal loss and PD susceptibility [10, 11]. The minor allele frequency of NMD3 rs34016896 was 0.41 in the Chinese PD population and 0.45 in the Chinese healthy population [11]. NMD3 encodes a ribosomebinding protein. Nmd3 is a structural mimic of eIF5A and activates the cpGTPase Lsg1 during 60S ribosome biogenesis [12]. Associations of NMD3 rs34016896 with clinical pathological phenotypes have been discovered. JM Shulman and colleagues found that NMD3 rs34016896 was related to the severity of nigral neuronal loss and not to Lewy bodies [13]. However, the function of NMD3 in PD is unknown. In addition, it is necessary to investigate the association between NMD3 and clinical symptoms of $\mathrm{PD}$, which could indicate the pathogenesis of PD.

In this study, we attempted to discover the clinical hallmarks of NMD3 rs34016896 $(\mathrm{C}>\mathrm{T})$ in southern Chinese PD patients.
201112, China

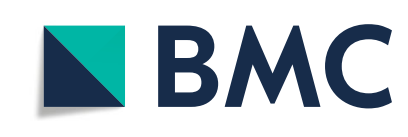

(c) The Author(s). 2020 Open Access This article is distributed under the terms of the Creative Commons Attribution 4.0 International License (http://creativecommons.org/licenses/by/4.0/), which permits unrestricted use, distribution, and reproduction in any medium, provided you give appropriate credit to the original author(s) and the source, provide a link to the Creative Commons license, and indicate if changes were made. The Creative Commons Public Domain Dedication waiver (http://creativecommons.org/publicdomain/zero/1.0/) applies to the data made available in this article, unless otherwise stated. 


\section{Methods}

\section{Study population}

PD patients were recruited from the outpatients clinic of Ren Ji Hospital (South Campus) and diagnosed by movement disorder specialists based on diagnostic criteria outlined by the Movement Disorders Society (MDS) [14]. For the PD patients, Hoehn-Yahr staging and their disease duration were recorded. A family history of PD was also recorded. Parkinsonism patients with secondary causes, such as inflammatory, drug-induced, vascular and toxin-induced parkinsonism, were excluded. Patients with parkinsonism with other neurodegenerative diseases, such as Wilson's disease, progressive supranuclear palsy, cerebral-basal degeneration and multiple system atrophy, were also excluded. This study was approved by the ethics committee of Ren Ji Hospital.

\section{Evaluation}

Each PD patient included in this study received an evaluation including the following rating scales: Unified PD Rating Scale provided by the Movement Disorders Society (MDS-UPDRS) was used to assess the status of PD [15]. The Mini-Mental State Examination (MMSE) and Beijing version of the Montreal Cognitive Assessment (MoCA) were adopted to assess cognitive function. The Sniffin' Sticks 16 (SS-16) was used to assess olfactory function [16]. The Hamilton Anxiety Rating Scale and Hamilton Depression Rating Scale were used to assess anxiety and depression, respectively. The non-motor symptoms scale (NMSS) was used to assess non-motor symptoms. The Scales for Outcomes in Parkinson's disease-Autonomic questionnaire (SCOPA-AUT) was used to assess autonomic symptoms. The 39-item Parkinson's Disease Questionnaire (PDQ-39) was used to assess the quality of life of the PD patients. The researchers received strict training regarding the use of these scales before assessing the $\mathrm{PD}$ patients. We also documented the presence (yes/no) of the following symptoms that were assessed by two individual neurologists: hallucination, apathy, excessive daytime sleepiness, pain, frequent urination, constipation, postural hypotension, sialorrhea, restless legs syndrome (RLS), delusion, double vision, decreased attention, decreased recent memory, nycturia, sexual dysfunction, hypogeusia, change in weight, daytime sweatiness, nocturnal sweatiness, urgent urination or urinary incontinence, sensitivity to light, sensitivity to cold, sensitivity to hot, anxiety, depression, and probable rapid eye movement sleep behaviour disorder (RBD). Probable RBD was diagnosed via the

Table 1 Demographic data and symptoms in PD patients involved in this study

\begin{tabular}{|c|c|c|c|}
\hline & NMD3 carriers $(n=178)$ & NMD3 wildtypes $(n=39)$ & $p$ value \\
\hline Age, mean (SD) & $57.03(10.16)$ & $55.69(10.24)$ & 0.461 \\
\hline Gender, female, N (\%) & $73(41.01)$ & $17(43.59)$ & 0.907 \\
\hline Disease duration, mean (SD) & $4.79(4.28)$ & $5.56(3.89)$ & 0.275 \\
\hline Family history, N (\%) & $17(9.55)$ & $5(12.82)$ & 0.550 \\
\hline Hoehn - Yahr staging, N (\%) & & & 0.869 \\
\hline 1.0 & $41(23.03)$ & $10(25.64)$ & \\
\hline 1.5 & $29(16.29)$ & $4(10.26)$ & \\
\hline 2.0 & $60(33.71)$ & $14(35.90)$ & \\
\hline 2.5 & $32(17.98)$ & $7(17.95)$ & \\
\hline 3.0 & $12(6.74)$ & $4(10.26)$ & \\
\hline 4.0 & $4(2.24)$ & $0(0.00)$ & \\
\hline 5.0 & $0(0.00)$ & $0(0.00)$ & \\
\hline MDS-UPDRS, mean (SD) & $48.34(27.10)$ & $43.05(20.51)$ & 0.175 \\
\hline Part I & $8.66(6.16)$ & $7.51(5.43)$ & 0.249 \\
\hline Part II & $11.60(7.71)$ & $10.08(5.81)$ & 0.168 \\
\hline Part III & $28.08(17.45)$ & $25.46(14.10)$ & 0.318 \\
\hline NMSS, mean (SD) & $36.23(35.57)$ & $31.03(27.42)$ & 0.315 \\
\hline SCOPA-AUT, mean (SD) & $10.92(9.06)$ & $9.08(8.56)$ & 0.233 \\
\hline PDQ-39, mean (SD) & $19.31(17.84)$ & $16.23(13.93)$ & 0.241 \\
\hline MMSE, mean (SD) & $26.31(3.79)$ & $27.44(2.89)$ & 0.042 \\
\hline MoCA, mean (SD) & $20.75(6.68)$ & $23.15(4.20)$ & 0.005 \\
\hline
\end{tabular}

MDS, movement disorders society; MMSE, Mini-Mental State Examination; MoCA, Montreal Cognitive Assessment; NMSS, non-motor symptoms scale; SCOPA-AUT, scales for Outcomes in Parkinson's disease - autonomic questionnaire; SD, standard deviation; PD, Parkinson's disease; PDQ-39, 39-item Parkinson's disease Questionnaire; UPDRS, unified Parkinson's disease rating scale 
RBD screening questionnaire [17]. We followed the method for detecting NMD3 rs34016896 described by $\mathrm{Li}$ and colleagues [18].

\section{Statistics}

The R stats (version 3.5.1) and CATT (version 2.0) packages were used to perform the statistical analyses. Student's $\mathrm{t}$ tests were performed to evaluate the differences in numeric variables between NMD3 carriers and wild types. For comparing categorical variables, chi-square tests were performed. The Cochran-Armitage test was used to assess ordinal variables between NMD3 carriers and wild types and an additive model of NMD3. Logistic regression was used to assess the association between the additive model/dominant model/recessive model/ overdominant model of $N M D 3$ and clinical phenotypes. The odds ratio (OR) and its 95\% confidence intervals
(CI) were also used. We also adjusted for age, sex and Hoehn-Yahr staging results.

\section{Results}

There were 217 PD patients included in this study. SNPs of two PD patients failed to be detected. In all, there were 39 NMD3 wild types and 178 NMD3 carriers in our study. The minor allele frequency in our group was 0.41 , which is similar to a previous genetic association study in southeastern China [11]. There was no difference in age, sex, disease duration, family history, and Hoehn-Yahr staging between the two groups. In the NMD3 wild-type group, the age was $55.69 \pm 10.24$ years (mean $\pm \mathrm{SD})$, and 17 (43.59\%) females were included in this group. In the NMD3 carrier group, the average age was $57.03 \pm 10.16$ years (mean $\pm \mathrm{SD}$ ), and $73(41.01 \%)$ females were included in this group. There were no

Table 2 The association between symptoms and genetic models (additive and dominant models) of NMD3 rs34016896

\begin{tabular}{|c|c|c|c|c|c|c|c|}
\hline & \multirow{2}{*}{$\begin{array}{l}\text { Additive } \\
\text { model }\end{array}$} & \multicolumn{3}{|c|}{ Dominant model } & \multicolumn{3}{|c|}{ Dominant model (adjusted)* } \\
\hline & & $p$ value & OR & $95 \% \mathrm{Cl}$ & $p$ value & OR & $95 \% \mathrm{Cl}$ \\
\hline Hallucination & 0.025 & 0.368 & 1.78 & $(0.58,7.79)$ & 0.341 & 1.86 & $(0.59,8.26)$ \\
\hline Apathy & 0.092 & 0.941 & 0.97 & $(0.49,1.97)$ & 0.955 & 0.98 & $(0.48,2.01)$ \\
\hline Excessive daytime sleepiness & 0.444 & 0.908 & 0.95 & $(0.38,2.15)$ & 0.896 & 0.94 & $(0.38,2.15)$ \\
\hline Pain & 0.696 & 0.474 & 0.77 & $(0.37,1.56)$ & 0.513 & 0.78 & $(0.37,1.60)$ \\
\hline Frequent urination & 0.639 & 0.491 & 1.28 & $(0.64,2.58)$ & 0.526 & 1.27 & $(0.60,2.72)$ \\
\hline Constipation & 0.930 & 0.656 & 0.85 & $(0.42,1.71)$ & 0.528 & 0.78 & $(0.36,1.66)$ \\
\hline Postural hypotension & 0.007 & 0.052 & 2.38 & $(1.05,6.16)$ & 0.050 & 2.43 & $(1.05,6.38)$ \\
\hline Sialorrhea & 0.487 & 0.600 & 1.20 & $(0.60,2.42)$ & 0.617 & 1.22 & $(0.56,2.62)$ \\
\hline RLS & 0.905 & 0.266 & 0.66 & $(0.32,1.40)$ & 0.259 & 0.65 & $(0.31,1.40)$ \\
\hline Delusion & 0.038 & 0.557 & 1.58 & $(0.42,10.33)$ & 0.605 & 1.51 & $(0.38,10.10)$ \\
\hline Double vision & 0.197 & 0.144 & 3.02 & $(0.85,19.31)$ & 0.133 & 3.22 & $(0.86,21.14)$ \\
\hline Decreased attention & 0.124 & 0.570 & 1.27 & $(0.58,3.00)$ & 0.554 & 1.29 & $(0.57,3.14)$ \\
\hline Decreased recent memory & 0.064 & 0.227 & 1.54 & $(0.76,3.09)$ & 0.232 & 1.54 & $(0.76,3.13)$ \\
\hline Nocturia & 0.870 & 0.845 & 1.08 & $(0.47,2.34)$ & 0.932 & 1.04 & $(0.43,2.36)$ \\
\hline Sexual dysfunction & 0.188 & 0.272 & 1.64 & $(0.71,4.27)$ & 0.254 & 1.69 & $(0.72,4.48)$ \\
\hline Hypogeusia & 0.202 & 0.827 & 1.08 & $(0.54,2.22)$ & 0.859 & 1.07 & $(0.53,2.19)$ \\
\hline Change of weight & 0.073 & 0.323 & 0.49 & $(0.13,2.38)$ & 0.298 & 0.47 & $(0.12,2.29)$ \\
\hline Daytime sweatiness & 0.449 & 0.964 & 1.02 & $(0.49,2.17)$ & 0.918 & 1.04 & $(0.49,2.29)$ \\
\hline Nocturnal sweatiness & 0.405 & 0.847 & 0.93 & $(0.46,1.96)$ & 0.874 & 0.94 & $(0.45,2.04)$ \\
\hline Urgent urination or urinary incontinence & 0.724 & 0.891 & 1.05 & $(0.52,2.10)$ & 0.946 & 1.03 & $(0.48,2.18)$ \\
\hline Sensitive to light & 0.142 & 0.387 & 2.50 & $(0.47,46.44)$ & 0.381 & 2.55 & $(0.46,47.88)$ \\
\hline Sensitive to cold & 0.484 & 0.589 & 1.30 & $(0.53,3.66)$ & 0.588 & 1.30 & $(0.53,3.68)$ \\
\hline Sensitive to hot & 0.481 & 0.311 & 0.63 & $(0.27,1.62)$ & 0.283 & 0.60 & $(0.25,1.59)$ \\
\hline Anxiety & 0.155 & 0.404 & 1.49 & $(0.62,4.19)$ & 0.335 & 1.64 & $(0.63,4.86)$ \\
\hline Depression & 0.935 & 0.644 & 1.35 & $(0.43,5.98)$ & 0.664 & 1.34 & $(0.41,6.09)$ \\
\hline RBD & 0.957 & 0.542 & 0.80 & $(0.39,1.67)$ & 0.498 & 0.77 & $(0.37,1.65)$ \\
\hline Olfactory dysfunction & 0.784 & 0.845 & 1.08 & $(0.47,2.34)$ & 0.934 & 1.03 & $(0.44,2.26)$ \\
\hline
\end{tabular}

$\mathrm{Cl}$, confidence interval; OR, odds ratio; RBD, rapid eye movement sleep behavior disorder; RLS, restless legs syndrome *adjusted by age, gender and Hoehn-Yahr staging 
differences in the total scores on the NMSS, SCOPAAUT, or PDQ-39 between the two groups. Cognitive function assessed by the MMSE and MoCA of the $N M D 3$ wild types was better than the NMD3 carriers (MMSE: $p=0.042, N M D 3$ wild type: $27.44 \pm 2.89$, NMD3 carriers: $26.31 \pm 3.79$; MoCA: $p=0.005, N M D 3$ wild type: $23.15 \pm 4.20, N M D 3$ carriers: $20.75 \pm 6.68$ ) (Table 1).

The presence of hallucination, postural hypotension, and delusion were associated with the additive model (hallucination: $p=0.025$; postural hypotension: $p=0.007$; and delusion: $p=0.038$ ). In addition, trends in the presence of apathy, decreased recent memory and weight change were found under the additive model (apathy: $p=0.092$; decreased recent memory: $p=0.064$; and change in weight: $p=0.073)$ (Table 2).
Under the dominant model, the presence of postural hypotension was found $(p=0.052$, OR: 2.38 , CI: $1.05-$ 6.16, before adjustment; $p=0.050$, OR: 2.43 , CI: $1.05-$ 6.38, after adjustment) (Table 2).

Under the recessive model, the presence of hallucination, apathy, postural hypotension and delusion were found (hallucination: $p=0.012$, OR: 2.96, CI: 1.29-7.10, before adjustment; $p=0.014$, OR: 2.95 , CI: 1.26-7.21, after adjustment; apathy: $p=0.011$, OR: $2.06, \mathrm{CI}: 1.18-3.61$, before adjustment; $p=0.012$, OR: 2.07 , CI: $2.28-3.67$, after adjustment; postural hypotension: $p=0.017$, OR: $2.04, \mathrm{CI}$ : $1.14-3.68$, before adjustment; $p=0.016$, OR: 2.08 , CI: 1.15-3.82, after adjustment; delusion: $p=0.014$, OR: 3.94 , CI: $1.38-12.92$, before adjustment; $p=0.012$, OR: 4.41 , 1.46-15.47, after adjustment). Trends for decreased attention, decreased recent memory, hypogeusia and change in

Table 3 The association between symptoms and genetic models (recessive models) of NMD3 rs34016896

\begin{tabular}{|c|c|c|c|c|c|c|}
\hline & \multicolumn{3}{|c|}{ Recessive model } & \multicolumn{3}{|c|}{ Recessive model (adjusted)* } \\
\hline & $p$ value & OR & $95 \% \mathrm{Cl}$ & $p$ value & OR & $95 \% \mathrm{Cl}$ \\
\hline Hallucination & 0.012 & 2.96 & $(1.29,7.10)$ & 0.014 & 2.95 & $(1.26,7.21)$ \\
\hline Apathy & 0.011 & 2.06 & $(1.18,3.61)$ & 0.012 & 2.07 & $(2.28,3.67)$ \\
\hline Excessive daytime sleepiness & 0.221 & 1.55 & $(0.78,3.19)$ & 0.213 & 1.56 & $(0.79,3.23)$ \\
\hline Pain & 0.252 & 1.39 & $(0.79,2.46)$ & 0.286 & 1.36 & $(0.77,2.42)$ \\
\hline Frequent urination & 0.879 & 1.04 & $(0.60,1.81)$ & 0.916 & 1.03 & $(0.57,1.86)$ \\
\hline Constipation & 0.629 & 1.15 & $(0.66,2.00)$ & 0.649 & 1.15 & $(0.64,2.07)$ \\
\hline Postural hypotension & 0.017 & 2.04 & $(1.14,3.68)$ & 0.016 & 2.08 & $(1.15,3.82)$ \\
\hline Sialorrhea & 0.536 & 1.19 & $(0.68,2.09)$ & 0.552 & 1.20 & $(0.65,2.23)$ \\
\hline RLS & 0.480 & 1.24 & $(0.68,2.26)$ & 0.520 & 1.22 & $(0.66,2.26)$ \\
\hline Delusion & 0.014 & 3.94 & $(1.38,12.92)$ & 0.012 & 4.41 & $(1.46,15.47)$ \\
\hline Double vision & 0.480 & 1.34 & $(0.58,3.02)$ & 0.420 & 1.43 & $(0.59,3.40)$ \\
\hline Decreased attention & 0.068 & 1.76 & $(0.96,3.26)$ & 0.075 & 1.78 & $(0.94,3.38)$ \\
\hline Decreased recent memory & 0.075 & 1.68 & $(0.96,3.00)$ & 0.069 & 1.71 & $(0.96,3.09)$ \\
\hline Nocturia & 0.930 & 1.03 & $(0.55,1.97)$ & 0.940 & 1.02 & $(0.52,2.03)$ \\
\hline Sexual dysfunction & 0.281 & 1.41 & $(0.75,2.63)$ & 0.317 & 1.39 & $(0.73,2.63)$ \\
\hline Hypogeusia & 0.086 & 1.63 & $(0.93,2.85)$ & 0.080 & 1.65 & $(0.94,2.89)$ \\
\hline Change of weight & 0.097 & 0.17 & $(0.01,0.94)$ & 0.089 & 0.16 & $(0.01,0.90)$ \\
\hline Daytime sweatiness & 0.247 & 0.71 & $(0.39,1.27)$ & 0.176 & 0.65 & $(0.35,1.20)$ \\
\hline Nocturnal sweatiness & 0.280 & 0.72 & $(0.40,1.29)$ & 0.199 & 0.67 & $(0.36,1.23)$ \\
\hline Urgent urination or urinary incontinence & 0.677 & 1.12 & $(0.65,1.96)$ & 0.718 & 1,12 & $(0.62,2.03)$ \\
\hline Sensitive to light & 0.151 & 2.38 & $(0.73,8.28)$ & 0.163 & 2.37 & $(0.71,8.50)$ \\
\hline Sensitive to cold & 0.541 & 1.24 & $(0.61,2.49)$ & 0.561 & 1.23 & $(0.60,2.47)$ \\
\hline Sensitive to hot & 0.809 & 0.91 & $(0.41,1.94)$ & 0.768 & 0.88 & $(0.39,1.96)$ \\
\hline Anxiety & 0.149 & 1.63 & $(0.83,3.20)$ & 0.143 & 1.72 & $(0.83,3.58)$ \\
\hline Depression & 0.626 & 0.79 & $(0.29,1.99)$ & 0.581 & 0.76 & $(0.27,1.99)$ \\
\hline RBD & 0.573 & 1.18 & $(0.66,2.10)$ & 0.591 & 1.18 & $(0.65,2.14)$ \\
\hline Olfactory dysfunction & 0.574 & 0.83 & $(0.45,1.58)$ & 0.593 & 0.84 & $(0.44,1.61)$ \\
\hline
\end{tabular}

$\mathrm{Cl}$, confidence interval; OR, odds ratio; RBD, rapid eye movement sleep behavior disorder; RLS, restless legs syndrome *adjusted by age, gender and Hoehn-Yahr staging 
weight were associated with the recessive model (decreased attention: $p=0.068$, OR: 1.76 , CI: $0.58-3.02$, before adjustment; $p=0.075$, OR: 1.78 , CI: $0.94-3.38$, after adjustment; decreased recent memory: $p=0.075$, OR: 1.68, CI: 0.96-3.00, before adjustment; $p=0.069$, OR: 1.71, CI: 0.96-3.09, after adjustment; hypogeusia: $p=0.086$, OR: 1.63 , CI: $0.93-2.85$, before adjustment; $p=0.080$, OR: $1.65, \mathrm{CI}: 0.94-2.89$, after adjustment; change in weight: $p=0.097$, OR: $0.17, \mathrm{CI}: 0.01-0.94$, before adjustment; $p=0.089$, OR: 0.16, CI: 0.01-0.90, after adjustment) (Table 3 ).

Under the overdominant model, an association with apathy and delusion were found (apathy: $p=0.011$, OR: 2.05 , CI: $1.19-3.57$, before adjustment; $p=0.012$, OR: 2.06 , CI: 1.18-3.64, after adjustment; delusion: $p=0.048$, OR: 3.66 , CI: 1.14-16.31, before adjustment; $p=0.035$, OR: 4.35 , CI: 1.25-20.99, after adjustment.). A trend for an association between hallucination and the overdominant model was found ( $p=0.071$, OR: 2.32 , CI: $0.97-6.17$, before adjustment; $p=0.086$, OR: 2.26, CI: 0.93-6.13, after adjustment) (Table 4).

We performed the Bonferroni correction following multiple comparisons to adjust $p$ values. After the correction, there were no remaining statistically significant results.

\section{Discussion}

Our study found that NMD3 carriers had worse cognitive function. The additive model of NMD3 was associated with hallucination, postural hypotension and delusion. The dominant model of NMD3 was associated with postural hypotension. The recessive model of NMD3 was associated with hallucination, apathy, postural hypotension and delusion. The overdominant

Table 4 The association between symptoms and genetic models (overdominant models) of NMD3 rs34016896

\begin{tabular}{|c|c|c|c|c|c|c|}
\hline & \multicolumn{3}{|c|}{ Overdominant model } & \multicolumn{3}{|c|}{ Overdominant model (adjusted)* } \\
\hline & $p$ value & OR & $95 \% \mathrm{Cl}$ & $p$ value & OR & $95 \% \mathrm{Cl}$ \\
\hline Hallucination & 0.071 & 2.32 & $(0.97,6.17)$ & 0.086 & 2.26 & $(0.93,6.13)$ \\
\hline Apathy & 0.011 & 2.05 & $(1.19,3.57)$ & 0.012 & 2.06 & $(1.18,3.64)$ \\
\hline Excessive daytime sleepiness & 0.198 & 1.54 & $(0.80,2.97)$ & 0.186 & 1.56 & $(0.81,3.03)$ \\
\hline Pain & 0.094 & 1.60 & $(0.92,2.76)$ & 0.121 & 1.55 & $(0.89,2.70)$ \\
\hline Frequent urination & 0.700 & 0.90 & $(0.53,1.54)$ & 0.698 & 0.89 & $(0.50,1.59)$ \\
\hline Constipation & 0.413 & 1.25 & $(0.73,2.15)$ & 0.349 & 1.32 & $(0.74,2.36)$ \\
\hline Postural hypotension & 0.414 & 1.27 & $(0.71,2.30)$ & 0.407 & 1.29 & $(0.71,2.36)$ \\
\hline Sialorrhea & 0.841 & 1.06 & $(0.61,1.82)$ & 0.845 & 1.06 & $(0.58,1.93)$ \\
\hline RLS & 0.121 & 1.62 & $(0.89,3.01)$ & 0.131 & 1.62 & $(0.87,3.06)$ \\
\hline Delusion & 0.048 & 3.66 & $(1.14,16.31)$ & 0.035 & 4.35 & $(1.25,20.99)$ \\
\hline Double vision & 0.625 & 0.82 & $(0.36,1.85)$ & 0.669 & 0.83 & $(0.35,1.98)$ \\
\hline Decreased attention & 0.176 & 1.53 & $(0.83,2.88)$ & 0.195 & 1.53 & $(0.81,2.97)$ \\
\hline Decreased recent memory & 0.416 & 1.25 & $(0.73,2.17)$ & 0.391 & 1.28 & $(0.73,2.23)$ \\
\hline Nocturia & 0.949 & 0.98 & $(0.52,1.83)$ & 0.998 & 1.00 & $(0.51,1.94)$ \\
\hline Sexual dysfunction & 0.839 & 1.07 & $(0.57,2.00)$ & 0.928 & 1.03 & $(0.54,1.97)$ \\
\hline Hypogeusia & 0.131 & 1.53 & $(0.88,2.66)$ & 0.114 & 1.56 & $(0.90,2.73)$ \\
\hline Change of weight & 0.304 & 0.51 & $(0.13,1.83)$ & 0.295 & 0.50 & $(0.12,1.82)$ \\
\hline Daytime sweatiness & 0.243 & 0.71 & $(0.40,1.26)$ & 0.157 & 0.65 & $(0.36,1.18)$ \\
\hline Nocturnal sweatiness & 0.363 & 0.77 & $(0.44,1.35)$ & 0.254 & 0.71 & $(0.39,1.28)$ \\
\hline Urgent urination or urinary incontinence & 0.763 & 1.09 & $(0.63,1.86)$ & 0.762 & 1.09 & $(0.61,1.97)$ \\
\hline Sensitive to light & 0.456 & 1.60 & $(0.49,6.14)$ & 0.481 & 1.58 & $(0.46,6.28)$ \\
\hline Sensitive to cold & 0.857 & 1.07 & $(0.53,2.16)$ & 0.880 & 1.06 & $(0.53,2.15)$ \\
\hline Sensitive to hot & 0.582 & 1.24 & $(0.59,2.69)$ & 0.579 & 1.25 & $(0.57,2.84)$ \\
\hline Anxiety & 0.442 & 1.30 & $(0.67,2.60)$ & 0.489 & 1.30 & $(0.63,2.75)$ \\
\hline Depression & 0.405 & 0.68 & $(0.27,1.69)$ & 0.376 & 0.65 & $(0.25,1.69)$ \\
\hline RBD & 0.306 & 1.35 & $(0.76,2.40)$ & 0.292 & 1.38 & $(0.76,2.51)$ \\
\hline Olfactory dysfunction & 0.483 & 0.80 & $(0.42,1.49)$ & 0.555 & 0.82 & $(0.43,1.56)$ \\
\hline
\end{tabular}

$\mathrm{Cl}$, confidence interval; $\mathrm{OR}$, odds ratio; $\mathrm{RBD}$, rapid eye movement sleep behavior disorder; RLS, restless legs syndrome *adjusted by age, gender and Hoehn-Yahr staging 
model of NMD3 was associated with apathy and delusion. Trends for associations between the additive model of NMD3 and apathy, decreased recent memory and change in weight were found. Trends for associations between the recessive model of $N M D 3$ and decreased attention, decreased recent memory, hypogeusia and change in weight were found. Trends for associations between the overdominant model of NMD3 and hallucination were found. To our knowledge, this is the first study to investigate the association between NMD3 and its clinical symptoms in Chinese PD patients.

NMD3 encodes a cytoplasmic protein for stable $60 \mathrm{~S}$ ribosomal subunits $[19,20]$. The function of ribosomes in the pathogenesis of PD remains unknown. A study revealed that parkin-PARIS (parkin-interacting substrate) played a deleterious role in rRNA transcription in PD patients, which indicated that ribosomes might be involved in the pathogenesis of PD [21]. A possible hypothesis of the function of NMD3 is that the dysfunction or dysregulation of ribosomes produces proteins relevant to PD. More relationships between the eukaryotic ribosome and PD should be discovered.

JM Shulman and colleagues found that NMD3 rs34016896 was associated with nigral neuronal loss and not with Lewy bodies [13]. This research indicated that NMD3 rs34016896 was associated with nigral neurodegeneration rather than the formation of Lewy bodies. Neuronal loss, especially dopaminergic neuronal loss, is associated with the pathogenesis of PD. However, we have little information regarding the details of the type of neurons for neuronal loss. To date, there have been no studies on the clinical phenotype based on the detailed pathological phenotypes. It is difficult to elucidate the impact of neuronal loss on clinical phenotypes. Further research on NMD3-related neuronal loss could uncover the presence of those relevant symptoms.

The strengths of our study are that PD were assessed by a structured scale, which is widely accepted. The diagnosis was based on MDS criteria. We also covered a wide-range assessment examining motor function, nonmotor symptoms and quality of life in PD patients.

This study has some weaknesses and limitations. First, we did not perform objective clinical methods, such as electrophysiology, to assess symptoms. Second, we did not perform stratifications due to the small sample size. Third, the sample of our study was small, and our study was a single-centre study. More multicentre and larger studies are warranted.

\section{Conclusions}

In conclusion, $N M D 3$ carriers had worse cognitive function. The additive model of NMD3 was associated with hallucination, postural hypotension and delusion. The dominant model of NMD3 was associated with postural hypotension. The recessive model of NMD3 was associated with hallucination, apathy, postural hypotension and delusion. The overdominant model of NMD3 was associated with apathy and delusion. More larger and multicentre studies are warranted. The recessive and overdominant model of NMD3 rs34016896 was associated with cognitive impairment in PD patients.

\begin{abstract}
Abbreviations
Cl: confidence interval; MDS: Movement Disorders Society; MMSE: MiniMental State Examination; MoCA: Montreal Cognitive Assessment; NMSS: non-motor symptoms scale; OR: odds ratio; PARIS: parkin-interacting substrate; PD: Parkinson's disease; PDQ-39: 39-item Parkinson's Disease Questionnaire; RBD: rapid eye movement sleep behaviour disorder; RLS: restless legs syndrome; SCOPA-AUT: Scales for Outcomes in Parkinson's disease-Autonomic questionnaire; SS-16: Sniffin' Sticks 16; UPDRS: Unified Parkinson's Disease Rating Scale
\end{abstract}

\section{Acknowledgements}

We thank all the patients who participated in this study.

\section{Authors' contributions}

$H W$ and $H \mathrm{~L}$ collected the PD and control data, performed the statistical analysis and drafted the manuscript. Zq S, Jj T, Sy M and Ty A collected the PD data.

$\mathrm{Zz} \mathrm{H}$ designed the study, supervised the study, doublechecked the statistical analysis and revised the manuscript. All authors have read and approved the manuscript.

\section{Funding}

This work was supported by grants from the National Natural Science Foundation of China [81801049] and the Minhang District Natural Science Research Project of Shanghai (grant no. 2016MHZ55). The two fundings supported the collection of the PD data.

\section{Availability of data and materials}

The datasets used and/or analysed during the current study are available from the corresponding author on reasonable request.

\section{Ethics approval and consent to participate}

This study was approved by the Research Ethics Committee, Renji Hospital, Shanghai, China. All participants signed consent forms. It also adhered to international guidelines established for scientific research involving human participants as established by the Declaration of Helsinki and its subsequent amendments.

\section{Consent for publication}

Not applicable.

\section{Competing interests}

The authors declare that there is no competing interests.

Received: 25 April 2019 Accepted: 15 December 2019

Published online: 14 January 2020

\section{References}

1. Zou YM, Liu J, Tian ZY, Lu D, Zhou YY. Systematic review of the prevalence and incidence of Parkinson's disease in the People's Republic of China. Neuropsychiatr Dis Treat. 2015;11:1467-72.

2. Béné R, Antić S, Budisić M, Lisak M, Trkanjec Z, Demarin V, Podobnik-Sarkanji S. Parkinson's disease. Acta Clin Croat. 2009:48(3):377-80.

3. Steece-Collier K, Maries E, Kordower JH. Etiology of Parkinson's disease: genetics and environment revisited. Proc Natl Acad Sci U S A. 2002;99(22): 13972-4.

4. Edwards TL, Scott WK, Almonte C, Burt A, Powell EH, Beecham GW, Wang L, Züchner S, Konidari I, Wang G, Singer C, Nahab F, Scott B, Stajich JM, Pericak-Vance M, Haines J, Vance JM, Martin ER. Genome-wide association study confirms SNPs in SNCA and the MAPT region as common risk factors for Parkinson disease. Ann Hum Genet. 2010;74(2):97-109. 
5. Hamza TH, Zabetian CP, Tenesa A, Laederach A, Montimurro J, Yearout D, Kay DM, Doheny KF, Paschall J, Pugh E, Kusel VI, Collura R, Roberts J, Griffith A, Samii A, Scott WK, Nutt J, Factor SA, Payami H. Common genetic variation in the HLA region is associated with lateonset sporadic Parkinson's disease. Nat Genet. 2010;42(9):781-5.

6. International Parkinson Disease Genomics Consortium, Nalls MA, Plagnol V, Hernandez DG, Sharma M, Sheerin UM, Saad M, Simón-Sánchez J, Schulte C, Lesage S, Sveinbjörnsdóttir S, Stefánsson K, Martinez M, Hardy J, Heutink P, Brice A, Gasser T, Singleton AB, Wood NW. Imputation of sequence variants for identification of genetic risks for Parkinson's disease: a meta-analysis of genome-wide association studies. Lancet. 2011;377(9766):641-9.

7. Blanca Ramírez M, Madero-Perez J, Rivero-Rios P, Martinez-Salvador M, Lara Ordonez AJ, Fernandez B, Fdez E, Hilfiker S. LRRK2 and Parkinson's disease: from lack of structure to gain of function. Curr Protein Pept Sci. 2017;18(7):677-86.

8. Siddiqui IJ, Pervaiz N, Abbasi AA. The Parkinson disease gene SNCA: evolutionary and structural insights with pathological implication. Sci Rep. 2016;6:24475.

9. Davis MY, Johnson CO, Leverenz JB, Weintraub D, Trojanowski JQ, ChenPlotkin A, Van Deerlin VM, Quinn JF, Chung KA, Peterson-Hiller AL, Rosenthal LS, Dawson TM, Albert MS, Goldman JG, Stebbins GT, Bernard B, Wszolek ZK, Ross OA, Dickson DW, Eidelberg D, Mattis PJ, Niethammer M, Yearout D, Hu SC, Cholerton BA, Smith M, Mata IF, Montine TJ, Edwards KL, Zabetian CP. Association of GBA mutations and the E326K polymorphism with motor and cognitive progression in Parkinson disease. JAMA Neurol. 2016;73(10):1217-24.

10. Liu ZH, Guo JF, Li K, Wang YQ, Kang JF, Wei Y, Sun QY, Xu Q, Wang DL, Xia K, Yan XX, Xu CS, Tang BS. Analysis of several loci from genome-wide association studies in Parkinson's disease in mainland China. Neurosci Lett. 2015;587:68-71.

11. Chen Y, Cao B, Ou R, Wei Q, Chen X, Zhao B, Wu Y, Song W, Shang HF. Determining the effect of the HNMT, STK39, and NMD3 polymorphisms on the incidence of Parkinson's disease, amyotrophic lateral sclerosis, and multiple system atrophy in Chinese populations. J Mol Neurosci. 2018;64(4):574-80.

12. Malyutin AG, Musalgaonkar S, Patchett $S$, Frank J, Johnson AW. Nmd3 is a structural mimic of elF5A, and activates the cpGTPase Lsg1 during 60S ribosome biogenesis. EMBO J. 2017;36(7):854-68.

13. Shulman JM, Yu L, Buchman AS, Evans DA, Schneider JA, Bennett DA, De Jager PL. Association of Parkinson disease risk loci with mild parkinsonian signs in older persons. JAMA Neurol. 2014;71(4):429-35.

14. Postuma RB, Berg D, Stern M, Poewe W, Olanow CW, Oertel W, Obeso J, Marek K, Litvan I, Lang AE, Halliday G, Goetz CG, Gasser T, Dubois B, Chan P, Bloem BR, Adler CH, Deuschl G. MDS clinical diagnostic criteria for Parkinson's disease. Mov Disord. 2015;30(12):1591-601.

15. Goetz CG, Tilley BC, Shaftman SR, Stebbins GT, Fahn S, Martinez-Martin P, Poewe W, Sampaio C, Stern MB, Dodel R, Dubois B, Holloway R, Jankovic J, Kulisevsky J, Lang AE, Lees A, Leurgans S, LeWitt PA, Nyenhuis D, Olanow CW, Rascol O, Schrag A, Teresi JA, van Hilten JJ, LaPelle N. Movement disorder society UPDRS revision task force. movement disorder societysponsored revision of the Unified Parkinson's Disease Rating Scale (MDSUPDRS): scale presentation and clinimetric testing results. Mov Disord. 2008;23(15):2129-70.

16. Chen W, Chen S, Kang WY, Li B, Xu ZM, Xiao Q, Liu J, Wang Y, Wang G, Chen SD. Application of odor identification test in Parkinson's disease in China: a matched case-control study. J Neurol Sci. 2012;316(1-2):47-50.

17. Shen SS, Shen Y, Xiong KP, Chen J, Mao CJ, Huang JY, Li J, Han F, Liu CF. Validation study of REM sleep behavior disorder questionnaire-Hong Kong (RBDQ-HK) in east China. Sleep Med. 2014;15(8):952-8.

18. Li G, Cui S, Du J, Liu J, Zhang P, Fu Y, He Y, Zhou H, Ma J, Chen S. Association of GALC, ZNF184, IL1R2 and ELOVL7 with Parkinson's disease in southern Chinese. Front Aging Neurosci. 2018;10:402.

19. Ho JH, Johnson AW. NMD3 encodes an essential cytoplasmic protein required for stable 605 ribosomal subunits in Saccharomyces cerevisiae. Mol Cell Biol. 1999;19(3):2389-99.

20. Oeffinger M. Joining the interface: a site for Nmd3 association on 605 ribosome subunits. J Cell Biol. 2010;189(7):1071-3.

21. Kang $\mathrm{H}$, Shin JH. Repression of rRNA transcription by PARIS contributes to Parkinson's disease. Neurobiol Dis. 2015;73:220-8.

\section{Publisher's Note}

Springer Nature remains neutral with regard to jurisdictional claims in published maps and institutional affiliations.

Ready to submit your research? Choose BMC and benefit from:

- fast, convenient online submission

- thorough peer review by experienced researchers in your field

- rapid publication on acceptance

- support for research data, including large and complex data types

- gold Open Access which fosters wider collaboration and increased citations

- maximum visibility for your research: over $100 \mathrm{M}$ website views per year

At BMC, research is always in progress.

Learn more biomedcentral.com/submissions 